\title{
Efficacy and safety of medicinal plants
}

\begin{abstract}
A review of the parameters that allow ensuring the efficacy and safety in the use of medicinal plants is made. The taxonomic identity of the species, the origin or provenance and the dose influence the response and contributes to the credibility of this natural medicine. It is necessary to advance in studies to achieve quality standards of each vegetable drug currently used.
\end{abstract}

Keywords: safety and efficacy, medicinal plants, ethnobotany
Volume 9 Issue 2 - 2018

\author{
Nélida Soria Rey \\ Faculty of Applied Sciences, National University of Pilar, Paraguay
}

Correspondence: Nélida Soria Rey, Faculty of Applied

Sciences, National University of Pilar, Scientific Society of

Paraguay, Paraguay, Email nsoria2000@yahoo.com

\section{Introduction}

The World Health Organization (WHO) considers Natural and Traditional Medicine, which includes the treatment with ethnomedicinal plants, as the most natural, safe and effective medicine, besides having a rational cost, being affordable and accepted by the population. WHO, therefore, supports Member States in promoting the use of Traditional Medicines in Primary Health Care (PHC), on the basis of ensuring the safety and quality of the medicine, while recommending professionals and consumers to use ethnomedicinal plants properly because they could be effective as first-line treatment and prevention for conditions such as colds, diarrhea, stomach pains, mild fevers, minor wounds, metabolic and other diseases.

\section{Efficacy and Safety}

In general, in Latin American countries, with a strong tradition in the use of ethnomedicinal plants, $99 \%$ of the population that goes to the health services, admit they use ethnomedicinal plants for medicinal or preventive purposes, although in general they do not inform health personnel of their use because they consider that consumption is harmless. It is important to remember that this medicine constitutes the only form of traditional medicine widely accepted by the population in all countries of Latin America. ${ }^{2}$

One of the current trends in medicine has been to incorporate Traditional Medicine into professional practice, not as an alternative method motivated by economic causes, but as a scientific discipline that must be studied, perfected and developed permanently, for its ethical and scientific advantages, because it constitutes a means of recovering the cultural heritage of the people, which is in danger of disappearing with the advance of "modern medicine". The above mentioned leads us to point out that public policies, which favor multidisciplinary investigations in ethnomedicinal plants, are needed, prior their use in primary care to ensure the use of a more effective and low-cost medicine. The efficacy and safety of ethnomedicinal plants is based on three fundamental pillars that can guarantee their innocuousness (Figure 1).

a. The taxonomic identity assures us, which species is used as medicinal. It is based on taxonomy and includes micrographic methods to certify the identity of the species used. The micrographic methods help to know the species that are used in traditional medicine, because plant organs are used that are not always recognized by the naked eye, only using these techniques is known the identity that assures us which is the species that we use. Thus, the botanical identity of the plant based drug must be given by the scientific name (genus, species, subspecies or variety, author and family) and the organ considered as medicinal must be described in detail, it may be important in addition to register the common names in the local language, if any. ${ }^{4}$ The substitution of one species for another produces different effects and causes the trust in the safety and efficacy of medicinal plants to be lost

b. In almost all countries of Latin America, ethnomedicinal plants come mostly from their natural habitat, and few are grown, probably due to the lack of knowledge of agricultural techniques for production. The species introduced and acclimated, in general, the conditions for their cultivation are known and it is important to remember that the ethnomedicinal plants constitute a significant commercial field, reason why the extensive exploitation of the species can take them to the limit of the extinction. ${ }^{5}$ Obtaining the raw material from its natural habitat can produce the substitution with native species similar to the one harvested, especially when the collection is done by unqualified people.

c. The dose used is the third factor that influences the safe and effective use of medicinal plants, is because people have a false idea that excessive consumption does not produce toxic effects, thinking that the medicine by being natural does not produce negative effects and they can consume the amount they want. In general, medicinal herbs are prepared in infusion or decoction for their consumption, the procedure is very important for the extraction of the active substances contained in them. When it comes to soft organs (leaf, flower, and aerial), the preparation is done by means of infusion, that is to say the water is boiled and it is fed on the vegetable, sometimes it is recommended to cover to avoid that the essential oils to be vaporized. When a hard part is used (bark, stem, root, and seed) it is boiled in the water for some minutes that can vary between five or ten, the resulting liquid is filtered and the decoction obtained is drunk. In general, the amount of the plant to be used depends on the plant organ used and the amount of water used is related to the contents of a $150 \mathrm{ml}$ cup. ${ }^{6,7}$ 
With regard to species activity, it is important to remember that the use of plants may interact with allopathic drugs. There are studies showing that the simultaneous consumption of medicine and organs, parts or products coming from ethnomedicinal plants may lead to interactions, which further motivates the need to recognize that plants should be treated as medicine. It is important to know the attitudes of users and health personnel regarding the consumption of ethnomedicinal plants as a medicine. ${ }^{8}$

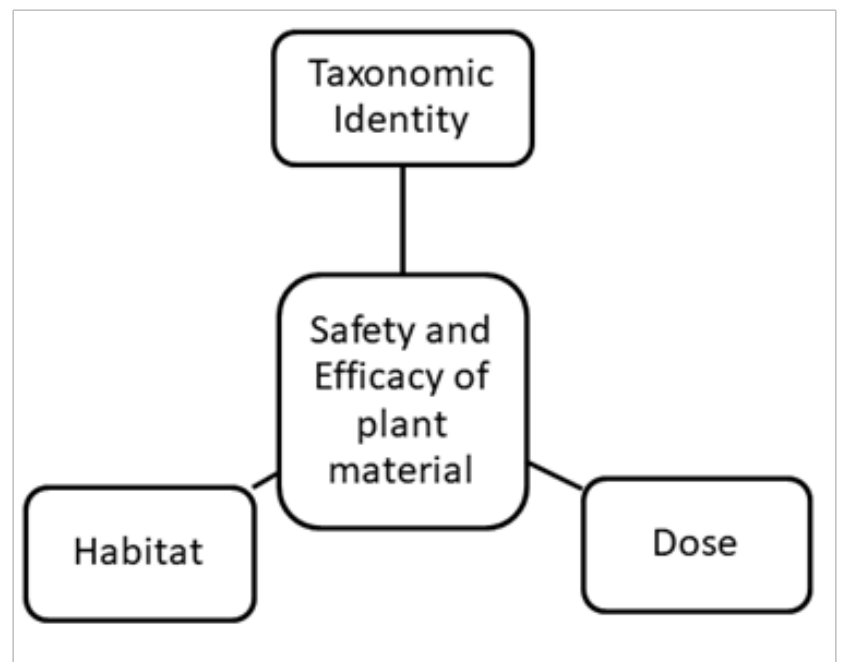

Figure I Parameters for the efficacy and safety of medicinal plants

\section{Conclusion}

The use of medicinal plants as a medicinal alternative is frequent in Latin America. For this medicine to be safe and effective, the parameters that were mentioned must be considered. It is necessary to continue the development of patterns for the Latin American Pharmacopoeia and of each country.

\section{Acknowledgements}

None.

\section{Conflict of interest}

The author declares there is no conflict of interest.

\section{References}

1. Del Toro García G, Trapero Quintana YM. Natural Medicine and Health System in Cuba. Bol Latinoam Caribe Plant Med Aromaticas. 2007;6(3):48-51.

2. Soria N, Ramos P. Use of medicinal plants in primary health care in Paraguay: some considerations for safe and effective use. Mem Inst Investig Cienc Salud. 2015;13(2):8-17.

3. Torres IB, Quintana IJ. Comparative analysis on the use of medicinal plants in traditional medicine in Cuba and Canary Islands. Rev Cubana Plant Med. 2008;9(1):9-14.

4. World Health Organization (WHO). Quality Control Methods for medicinal plant materials. Geneva, Switzerland. 2005:122.

5. World Health Organization (WHO). WHO Guidelines on Good Agricultural Practices and Collection (BPAR) for Medicinal Plants. Geneve, Switzerland. 2003:79.

6. Tyler VE, Robbers JE. Las hierbas medicinales de TYLER. Therapeutic use of phytomedicines. Acribia SA. 2003:254.

7. National Formulary of Phytotherapy of Brazil. Brasilia. 2011:560.

8. http/:www.uva.org.Ar/cuba 